\title{
Genetic relationships between Lolium (Poaceae) species revealed by RAPD markers
}

\author{
X. Ma*, X.-Y. Gu*, T.-T. Chen, S.-Y. Chen, L.-K. Huang and X.-Q. Zhang \\ Department of Grassland Science, Animal Science and Technology College, \\ Sichuan Agricultural University, Ya’an, Sichuan, China \\ *These authors contributed equally to this study. \\ Corresponding author: X.-Q. Zhang \\ E-mail: zhangxq8@hotmail.com
}

Genet. Mol. Res. 12 (3): 3246-3255 (2013)

Received June 14, 2012

Accepted October 29, 2012

Published March 11, 2013

DOI http://dx.doi.org/10.4238/2013.March.11.4

\begin{abstract}
The genus Lolium is one of the most important groupings of temperate forage grasses, including about eight recognized species that are native to some temperate and subtropical regions of the northern hemisphere. We examined genetic relationships among 18 accessions representing all Lolium species using RAPD markers. Among 50 random primers that we screened, 13 gave reproducible amplification banding patterns. Each of these 13 primers generated 1943 scorable fragments. A total of 367 RAPD fragments were detected, of which $95.9 \%$ were polymorphic across all the Lolium accessions. Dice's coefficient of dissimilarity ranged from 0.016 to 0.622 , which is indicative of substantial genetic variations in these Lolium accessions. A neighbor-joining cluster analysis, with bootstrap permutation, produced an unrooted dendrogram, which grouped 18 accessions into two main clades, supporting high bootstrap values (98 and 96\%). The first clade included the self-pollinated species, $L$. persicum, L. temulentum, $L$. remotum, and $L$. subulatum. The cross-pollinated species, i.e., $L$. multiflorum, L. perenne, $L$. rigidum, and $L$. canariense, composed the second clade, in which $L$. canariense formed a distinct subclade, indicating its higher genetic separation from other allogamous species.
\end{abstract}


The value of $r=0.97$ in the Mantel test for cophenetic correlation applied to the cluster analysis indicated the high degree of fit of the accessions to a group. A principal coordinate analysis, whose first three coordinates explained $72.6 \%$ of the variation, showed similar groupings as in the cluster analysis. The genetic relationships estimated by the polymorphism of RAPD markers are basically in agreement with those previously inferred with other genetic markers.

Key words: Lolium; RAPD markers; Taxonomy; Genetic relationship; Polymorphism

\section{INTRODUCTION}

The genus Lolium L. (Poaceae) is native to Europe, temperate Asia, and North Africa but has been widely distributed throughout temperate regions of the world (Charmet et al., 1996). It includes two of the most economically important forage grasses, namely Italian ryegrass $(L$. multiflorum) and perennial ryegrass (L. perenne), which are both widely grown as forage or turf grasses, especially in Europe, New Zealand, Australia, and other temperate/Mediterranean regions of the world. Generally, eight species are recognized: L. perenne L., L. multiflorum Lam., L. rigidum Gaud., L. canariense Steud., L. persicum Boiss. \& Hohen. ex Boiss., L. remotum Schrank, L. temulentum L., and L. subulatum Vis. (= L. loliaceum Hand.-Mazz.), according to their reproduction manner in addition to morphological characters such as spike and leaf morphology and growth habit as well (Terrell, 1968). The first 4 species are wind-pollinated outbreeders, the latter 4 are self-pollinated species (Fearon et al., 1983; Jauhar, 1993), although $L$. canariense has been found to be partially cross-pollinated (Charmet and Balfourier, 1994). The Lolium species occur as diploid $(2 \mathrm{n}=14)$ (Terrell, 1968), but due to breeding activities, many tetraploid cultivars have been developed in the fodder crop species, perennial, and Italian ryegrass (Loos, 1993b). Besides, the outbreeding Lolium species are closely related to members of the genus Festuca of the section Bovinae, and they hybridize fairly easily with them (Borrill, 1976).

In spite of intensive breeding activities and advanced research aimed at improving the turf quality or forage yield, very little attention has been paid to the phylogenetic relationships within the genus Lolium. A better knowledge of the genetic relationships between Lolium species is of both theoretical and practical importance, which can serve as the basis of the taxonomic system and provide explicit information for a more efficient exploitation and utilization of genetic resources through hybridization by ryegrass breeders (Charmet and Balfourier, 1994).

Notwithstanding slight controversies, the previous results of some studies consistently support the notion that the genus Lolium can be divided into two groups based on reproduction mode: one for the cross-breeding species and another for the remaining inbreeding species (Charmet and Balfourier, 1994; Stammers et al., 1995; Charmet et al., 1997; Gaut et al., 2000; Polok et al., 2006). As Lolium is believed to be of extremely recent origin, its phylogeny has not been resolved with certainty (Gaut et al., 2000). This contributes greatly to the ambiguity of the taxonomic classification of the genus. A big challenge underlying the genus Lolium is in determining whether L. perenne (Bulinska-Radomska and Lester, 1988; Catalán, et al., 1997) or L. rigidum (Charmet and Balfourier, 1994) is the common ancestor of the genus. Another point at issue is that the phylogenetic placement of L. canariense and L. subulatum is delphic, 
probably because neither of these species has been included in many analyses (Gaut et al., 2000). It is a pity that most conclusions about Lolium phylogeny are based on morphology, cytogenetic analysis, or the number of isozyme loci. Morphology alone has failed to clearly resolve phylogenetic relationships owing to overlapping ranges of variation (Polok, 2007). The advent of molecular data has revolutionized the field of plant systematics and has led to new insights into phylogenetic relationships at all taxonomic levels. In previous molecular studies of Lolium phylogeny, most of the data employed were from the chloroplast genome or internal transcribed spacer (ITS) sequence (Darbyshire and Warwick, 1992; Catalán et al., 1997; Gaut et al., 2000; Balfourier et al., 2000; McGrath et al., 2007), whereas methods based on genome scanning molecular markers were rarely reported (Stammers et al., 1995; Polok et al., 2006). DNA marker-based fingerprinting is not typically influenced by environmental conditions, and therefore can be used to rapidly distinguish species using small amounts of DNA and to deduce reliable information on their phylogenetic relationships. Among available molecular markers, RAPD (random amplified polymorphic DNA) (Williams et al., 1990) is an inexpensive and rapid method not requiring any information regarding the genome of the plant, and has provided a powerful tool for the investigation of genetic variability in numerous plants. The aim of the present study was to use RAPD markers to estimate the level of genetic variation of Lolium and to detect phylogenetic relationships between 8 acknowledged ryegrass species.

\section{MATERIAL AND METHODS}

\section{Plant material and RAPD amplification}

Eighteen accessions belonging to the 8 species of Lolium were employed as the study material (Table 1). All were obtained from the National Plant Germplasm System, USA. Genomic DNA was extracted from fresh young leaves of ten individuals of a species using the CTAB protocol (Doyle and Doyle, 1990). DNA concentration was measured using a NanoDrop ND 1000 spectrophotometer (NanoDrop Technologies, Inc.) and 0.8\% agarose gel electrophoresis. DNA was diluted in water to a final concentration of $10 \mathrm{ng} / \mu \mathrm{L}$.

\begin{tabular}{|c|c|c|c|}
\hline No. & Voucher entry & Species & Origin \\
\hline 1 & PI598452 & L. perenne $\mathrm{L}$. & Wales, United Kingdom \\
\hline 2 & PI277847 & L. perenne L. & Turkey \\
\hline 3 & PI610828 & L. perenne $\mathrm{L}$. & Wales, United Kingdom \\
\hline 4 & PI272118 & L. multiflorum Lam. & Poland \\
\hline 5 & PI376874 & L. multiflorum Lam. & New Zealand \\
\hline 6 & PI632537 & L. multiflorum Lam. & Oregon, United States \\
\hline 7 & PI239753 & L. rigidum Gaud. & Algeria \\
\hline 8 & PI239731 & L. rigidum Gaud. & Fouka, Egypt \\
\hline 9 & PI239795 & L. rigidum Gaud. & Mosj.-Gol, Iran \\
\hline 10 & PI422589 & L. temulentum $\mathrm{L}$. & Tetouan, Morocco \\
\hline 11 & PI218085 & L. temulentum L. & Peshawar, Pakistan \\
\hline 12 & PI302664 & L. temulentum L. & India \\
\hline 13 & PI545637 & L. persicum Boiss. \& Hohen. & Golbasi, Turkey \\
\hline 14 & PI545664 & L. persicum Boiss. \& Hohen. & Yesilova, Turkey \\
\hline 15 & PI545676 & L. persicum Boiss. \& Hohen. & Agri, Turkey \\
\hline 16 & PI197310 & L. subulatum Vis. & Argentina \\
\hline 17 & PI320544 & L. canariense Steud. & Canary Islands, Spain \\
\hline 18 & PI283611 & L. remotum Schrank & France \\
\hline
\end{tabular}


Fifty random primers (Operon Technologies, Almeda, CA, USA) were initially screened on a sample of the accessions. Primers that produced reproducible, polymorphic bands were used to amplify the rest of the accessions. PCR amplifications were carried out in an MJ Research Thermal Cycler PTC-200, in a reaction volume of $20 \mu \mathrm{L}$ containing $20 \mathrm{mM}$ Tris- $\mathrm{HCl}, \mathrm{pH} 8.4,50 \mathrm{mM} \mathrm{KCl}, 2 \mathrm{mM} \mathrm{MgCl}, 0.2 \mu \mathrm{M}$ primer, $0.1 \mathrm{mM}$ of each dNTP, 0.5 U Taq DNA polymerase (TaKaRa, Japan), and 20 ng template DNA. The amplification reaction profile was: an initial denaturation at $94^{\circ} \mathrm{C}$ for $5 \mathrm{~min}$ followed by 40 cycles at $94^{\circ} \mathrm{C}$ for $1 \mathrm{~min}, 36^{\circ} \mathrm{C}$ for $1 \mathrm{~min}$, and $72^{\circ} \mathrm{C}$ for $2 \mathrm{~min}$, and a final 7 -min extension at $72^{\circ} \mathrm{C}$. The RAPD products were electrophoresed on a $1.5 \%$ agarose gel in $0.5 \mathrm{X}$ TBE (Tris-boric acid-EDTA) buffer at $100 \mathrm{~V}$ for $3.5 \mathrm{~h}$. The gels were stained in 0.2 $\mu \mathrm{g} / \mathrm{mL}$ ethidium bromide and photographed using a gel documentation system (Gel Doc BioRad 2000). Each assay was repeated twice, and only stable products were scored. A 100-bp DNA ladder was used as the molecular standard to confirm the appropriate RAPD markers.

\section{Data analysis}

RAPD assays were performed in duplicate, and only those reproducible patterns clearly obtained were scored. It was assumed that bands of the same molecular weight in different samples were identical. The presence or absence of each amplified band was recorded as 1 (present) or 0 (absent) and treated as binary characters. For considering a marker as polymorphic, the absence of an amplified product in at least one species was used as a criterion. The polymorphism information content (PIC) for each RAPD marker was calculated with the formula: $\mathrm{PIC}_{i}=2 f_{\mathrm{i}}\left(1-f_{\mathrm{i}}\right)$, where $P I C_{i}$ is the polymorphic information content of marker $i, f_{i}$ is the frequency of the marker bands that were present, and $\left(1-f_{i}\right)$ is the frequency of marker bands that were absent (Roldán-Ruiz et al., 2000). PIC values for dominant marker bands such as RAPD markers have a maximum of 0.5 for $f_{i}$ $=0.5$.

A binary matrix was used to estimate genetic distances between pairs by employing the Dice distance coefficient (Nei and Li, 1979). A dendrogram was constructed by the neighbor-joining (NJ) method, and the original binary matrix was bootstrapped 1000 times to measure the reliability of the branching patterns and the quality of the resulting phylogenetic groups. DARwin version 5.0 (Perrier et al., 1999) was used for the above calculations. The Mantel test (Mantel, 1967) was used to test the significance of the correlation coefficient between pairs of similarity matrices and cophenetic matrices and for determining cophenetic correlation values using NTSYS pc version 2.2 (Rohlf, 1998). Principal coordinate analysis (PCoA) was carried out by the NTSYS pc version 2.2 software to provide a graphical representation of the genetic relationships between the ryegrass accessions studied.

\section{RESULTS}

\section{RAPD polymorphism and genetic variation}

Fifty random decamer primers were used in this study, of which 13 were chosen for 
analysis based on a reproducible and well-resolved RAPD pattern (Table 2). The size of the amplified products mainly ranged from 150 to 1800 , with 19-43 bands per primer. A total of 367 RAPD polymorphic bands were generated by the 13 primers, at a rate of 28.2 bands per primer, of which 352 bands were found to be polymorphic. The percentage of polymorphic bands varied from 82.4 to $100 \%$ with an average of $95.9 \%$ for all primers, which could even be comparable with $98.8 \%$ polymorphism in characterizing some Lolium species by AFLP analysis (Polok et al., 2006). This result indicated that the genus Lolium possesses a high level of genetic diversity and abundant genetic variation. PIC scores per primer across the genus varied from 0.281 (OPB05) to 0.390 (OPAH08) with an average of 0.339 , reflecting the same information to polymorphism ratio.

Table 2. Sequences of the primers and the results of amplification.

\begin{tabular}{|c|c|c|c|c|c|}
\hline Primer & Sequence $\left(5^{\prime} \rightarrow 3^{\prime}\right)$ & Band size (bp) & Total bands & Polymorphism ratio (\%) & PIC \\
\hline OPA01 & CAGGCCCTTC & $170-2200$ & 20 & 100.0 & 0.311 \\
\hline OPA07 & GAAACGGGTG & $180-1750$ & 28 & 92.9 & 0.289 \\
\hline OPA16 & AGCCAGCGAA & $120-1360$ & 43 & 97.7 & 0.371 \\
\hline OPB05 & TGCGCCCTTC & $210-2300$ & 26 & 100.0 & 0.281 \\
\hline OPB18 & CCACAGCAGT & $140-1850$ & 34 & 82.4 & 0.357 \\
\hline OPC04 & CCGCATCTAC & $190-1650$ & 22 & 86.4 & 0.313 \\
\hline OPD15 & CATCCGTGCT & $130-1500$ & 27 & 100.0 & 0.365 \\
\hline OPQ20 & TCGCCCAGTC & $250-1850$ & 19 & 94.7 & 0.336 \\
\hline OPR10 & CCATTCCCCA & $130-1900$ & 26 & 96.2 & 0.343 \\
\hline OPAH02 & CACTTCCGCT & $140-1850$ & 32 & 100.0 & 0.377 \\
\hline OPAH06 & GTAAGCCCCT & $120-1650$ & 33 & 97.0 & 0.357 \\
\hline OPAH08 & TTCCCGTGCC & $180-1580$ & 29 & 100.0 & 0.390 \\
\hline OPAH15 & CTACAGCGAG & $140-1800$ & 28 & 100.0 & 0.321 \\
\hline Total & - & - & 367 & - & - \\
\hline Means & - & - & 28.2 & 95.9 & 0.339 \\
\hline
\end{tabular}

$\mathrm{PIC}=$ polymorphism information content.

\section{Genetic relationships between species}

The Nei-Li (Dice) distance matrix developed using the NTSYS software showed that distance index ranged from 0.016 to 0.622 with a mean of 0.458 , thereby suggesting high levels of genetic variability in the species. The highest genetic distance value $(0.622)$ was found between PI239753 (L. rigidum) and PI283611 (L. remotum), implying the farthest genetic relationship, and the lowest value (0.016) was found between PI218085 (L. temulentum), and PI302664 (L. temulentum), disclosing the closest genetic relationship among the 18 accessions tested. In addition, mean genetic distances among Lolium species was also calculated by averaging the values of the accessions within a given species. The highest interspecific genetic distance was 0.616 between $L$. rigidum and $L$. remotum, and the lowest interspecific distance was 0.318 between L. temulentum and L. persicum.

The distance matrix based on the Dice genetic distance is graphically represented as a dendrogram using the NJ method, since this method is less sensitive to varying mutation rates (Figure 1). A cophenetic correlation coefficient of 0.97 was obtained between the Dice dissimilarity matrix and the derived NJ cophenetic matrix, revealing a good fit between the dendrogram clusters and the dissimilarity matrices. According to the dendrogram, all 18 accessions of the 8 species were separated into 2 distinct 
clusters. The first cluster (Cluster I) was composed of the self-pollinated species $L$. temulentum, $L$. persicum, $L$. remotum, and L. subulatum, which was subdivided into 2 subgroups and strongly supported by a $98 \%$ bootstrap value. The first subclade included L. persicum, L. temulentum, and L. remotum, supported by a $100 \%$ bootstrap value; the second subclade was formed by L. subulatum, which showed the greatest distance from the other three inbreeders. The second cluster (Cluster II) comprised four cross-pollinated species, L. perenne, L. multiflorum, L. rigidum, and L. canariense, which was divided into 2 subclusters and was supported by a $96 \%$ bootstrap value. $L$. canariense formed a single subclade and it was clearly differentiated from the other 3 species in Cluster II. Furthermore, accessions within species always tended to first group together and then to related species.

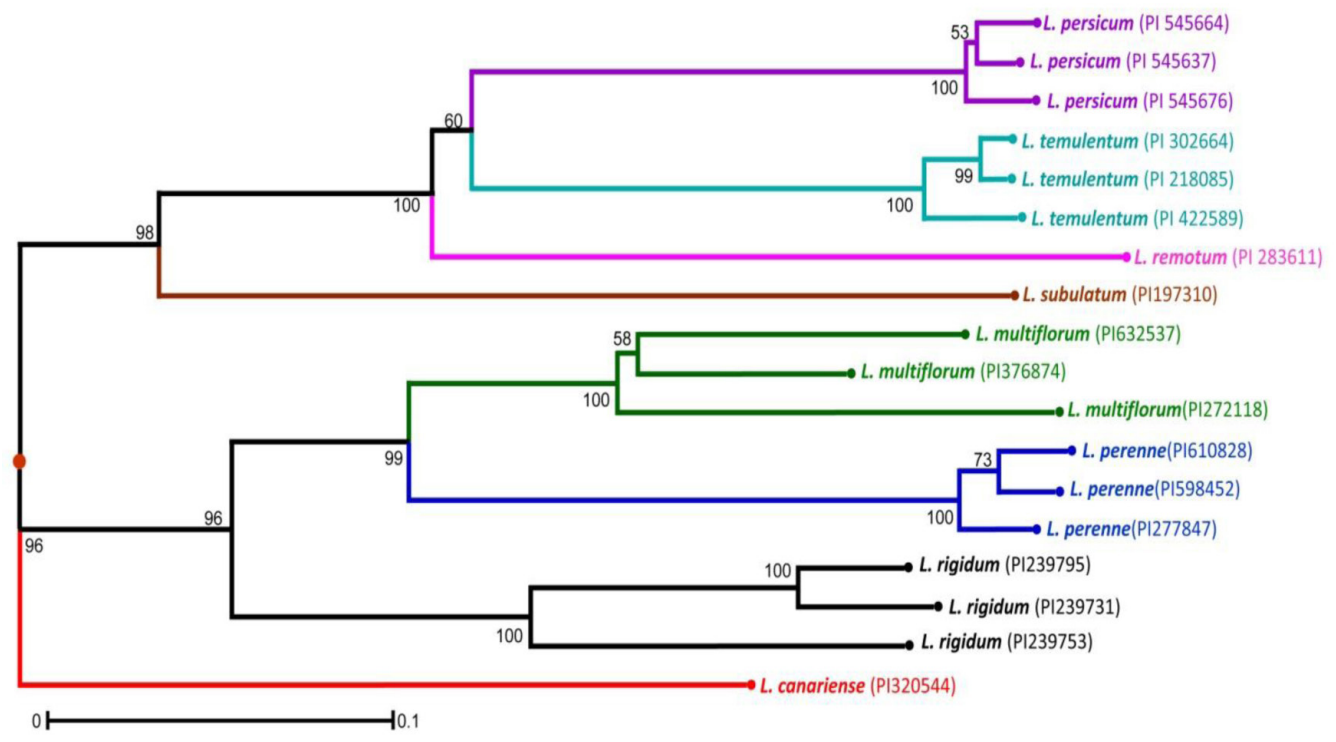

Figure 1. Unrooted dendrogram constructed using the neighbor-joining method from the RAPD data matrix calculated with the formula given by Nei and $\mathrm{Li}(1979)$. The numbers at the tree nodes are bootstrap values reported as percentage.

It is worth comparing results from various methods of multivariate analysis to verify conclusions. Therefore, besides the cluster analysis, we also performed PCoA, again based on the matrix derived from the Dice distance coefficients (Figure 2). The first three principal coordinates accounted for $46.85,14.96$, and $10.83 \%$ of total variation, respectively. The autogamous section and the allogamous section were clearly separated in the projection onto the first principal coordinate (axis 1). The interspecies and intraspecies relationships were well reflected according to the second and third coordinates (axes 2 and 3) (Figure 2). Overall, clustering results based on the NJ method were corroborated by the PCoA ordination method. 


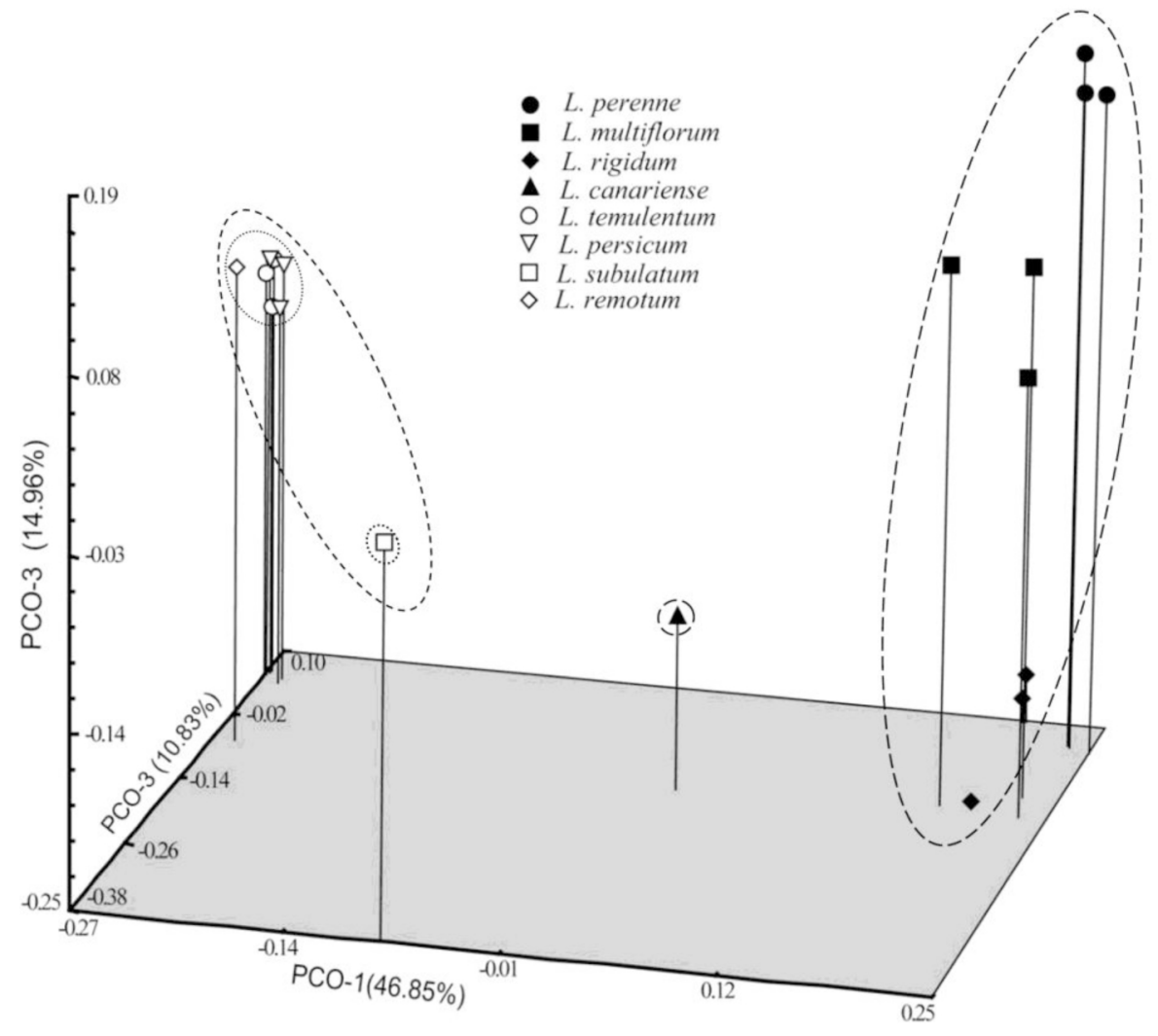

Figure 2. Principle coordinate plot for the first three principal coordinates estimated for RAPD markers of the eight Lolium species.

\section{DISCUSSION}

The RAPD technique has been successfully employed in taxonomic and genetic diversity studies of some Lolium species due to the simplicity, low cost and non-requirement of DNA sequence information prior to application (Stammers et al., 1995; Vieira et al., 2004; Bolaric et al., 2005). The genetic validity of RAPD markers has been questioned, because co-migrating bands may correspond to non-homologous DNA sequences. However, several authors (Stammers et al., 1995; Lannér et al., 1996) have checked the homology of RAPD bands by hybridization with RAPD fragments used as probes and have found low error rates, which are not likely to significantly affect estimates of genetic relatedness. Moreover, another problem of low reproduction (stability) of RAPD assay could be well solved using high-quality DNA samples, an optimized reaction system and program in a standard operation. In the present study, RAPD on bulked total DNA (Yu and Pauls, 1993; Charmet et al., 1997) proved to be an efficient tool in estimating overall genetic similarities between ryegrass accessions, and gave highly correlated estimates of genetic distances. Furthermore, bootstrap re-sampling 
from the combination of RAPD bands provided fairly good coefficients of variation.

Owing to the difficulty of sampling accessions within some Lolium species, the taxa under study may not adequately represent the breadth of phylogenetic diversity. Nonetheless, this study of 18 accessions covered, to our knowledge, all of the eight recognized Lolium species studied with various methods to date. Although this sample is insufficient to illustrate fine details about the evolution of the genus Lolium, the sample is sufficient to yield new insights into species' broad phylogenetic trends. In the present investigation, phylogenetic analysis of the dissimilarity matrix based on RAPD markers could readily divide the Lolium species into a self-pollinated section and another cross-pollinated one. This segregation coincides strongly with previous studies using isozyme (Charmet and Balfourier, 1994), ITS sequence (Charmet et al., 1997; Gaut et al., 2000), RFLP (Charmet et al., 1997), RAPD (Stammers et al., 1995), and morphological data (Mirjalili et al., 2008). In general, the autogamous group can be well separated from the allogamous group by botanical characters. For instance, the inbreeders are on average smaller, contain fewer florets, and have ears emerging earlier (Loos, 1993a). This strong differentiation or distinction between self- and cross-pollinated species may result from their different divergence time. The Lolium species appeared to be of recent origin (Stammers et al., 1995), and the self-fertilizing species diverged first from the common ancestor and the cross-pollinated species last (Charmet et al., 1997). Last but not least, it should be pointed out that UPGMA clustering was not utilized on RAPD data, because the assumption of a "molecular clock" can hardly be made for RAPD (Charmet et al., 1997).

In the self-fertilized cluster on the RAPD-based dendrogram, L. persicum was closer to L. temulentum than either of these 2 species was to L. remotum. This observation is confirmed by previous results based upon analysis of plant morphology (Loos, 1993a), isozyme (Loos, 1993b), AFLP (Polok et al., 2006), and ITS sequence (Charmet et al., 1997). L. subulatum has been viewed as intermediate between the cross-breeding and the inbreeding group (Charmet et al., 1997). According to the present investigation, L. subulatum is a species distinct from the other three inbreeders. However, there is no strong consensus on the phylogenetic position of L. subulatum, not only because this species can be closely related to allogamous Lolium species in some studies (Gaut et al., 2000; Polok, 2007), but because this species has been rarely included in analyses. To date, L. temulentum and L. remotum are known only as weeds of crops, and have been progressively disappearing by widespread use of farm chemicals. Since they possess the valuable sources of self compatibility genes to transfer to outbreeders, their conservation for germplasm resources must be considered (Thorogood and Hayward, 1992).

In the cross-pollinated group on the RAPD-based dendrogram, L. multiflorum and $L$. perenne are the closest related species, and L. rigidum is relatively close to both of them, while L. canariense formed the most distant subclade. Cytological (Naylor, 1960) and electrophoretic (Bulinska-Radomska and Lester, 1985) evidence suggests that L. perenne, L. multiflorum, and $L$. rigidum should be regarded as a subspecies of one biological species, as they are all interfertile, providing that flowering dates are compatible. However, the present observation indicated that these three outbreeding species can be well separated in spite of the overlap of distribution range, morphological variation, and limited natural hybridization and introgression (Loos, 1993a,b; Charmet and Balfourier, 1994; Charmet et al., 1996; Bennett et al., 2000). A high level of intraspecific variation of L. multiflorum inferred from branch length of the NJ tree was found, which is common to morphological studies (Bennett et al., 2000). This may correspond to its multifold form life cycle, since L. multiflorum is not a true annual and may 
behave as a biennial or short-lived perennial depending on environmental conditions (Terrell, 1968). Close association between these three species and possible recent evolutionary divergence (Stammers et al., 1995; Charmet et al., 1997) have resulted in varying degrees of similarity between them. Interestingly, according to RAPD (Stammers et al., 1995) or AFLP data (Polok et al., 2006), L. multiflorum has a position closer to L. perenne than to L. rigidum, while according to the isozyme data, $L$. multiflorum is closer to L. rigidum than to L. perenne (Charmet and Balfourier, 1994; Bennett et al., 2002). Different clustering methods and/or characteristics of genetic markers may be responsible for the above controversy.

According to our investigation, $L$. canariense has a distant relationship with other typical allogamous species despite forming the same cluster. This could be confirmed by analyses of isozymes (Charmet and Balfourier, 1994), ITS sequence (Gaut et al., 2000), and RFLP marker of cpDNA (Charmet et al., 1997). L. canariense is generally considered an autogamous species but is also supposed to be intermediate with respect to the mode of reproduction due to partial cross-pollination (Charmet et al., 1994). Furthermore, strictly annual L. canariense is endemic to the Canary Islands in the Atlantic Ocean, which may suffer severe bottleneck effects in speciation (Francisco-Ortega et al., 2000). This may lead to the formation of a distinct gene pool of $L$. canariense relative to other cross-pollinated Lolium species.

In conclusion, the RAPD marker-based study of genetic variations facilitates the delineation of Lolium species. The use of molecular markers with good stability and high polymorphism, such as SSR or AFLP, and DNA sequence-based analyses in future studies that include additional accessions representing a broader geographic distribution, should allow us to elucidate the systematic positions and origins of Lolium species.

\section{ACKNOWLEDGMENTS}

Research supported by the National Key Technology Research and Development Program of China (\#2011BAD17B03), the Earmarked Fund for Modern Agro-Industry Technology Research System (\#CARS-35-5), and the Sichuan Provincial Crop Breeding Project (\#2011NZ0098-11), China.

\section{REFERENCES}

Balfourier F, Imbert C and Charmet G (2000). Evidence for phylogenetic structure in Lolium species related to the spread of agriculture in Europe. A cpDNA study. Theor. Appl. Genet. 101: 131-138.

Bennett SJ, Hayward MD and Marshall DF (2000). Morphological differentiation in four species of the genus Lolium. Genet. Resour. Crop Ev. 47: 247-255.

Bennett SJ, Hayward MD and Marshall DF (2002). Electrophoretic variation as a measure of species differentiation between four species of the genus Lolium. Genet. Resour. Crop Ev. 49: 59-66.

Bolaric S, Barth S, Melchinger AE and Posselt UK (2005). Molecular genetic diversity within and among German ecotypes in comparison to European perennial ryegrass cultivars. Plant Breed. 124: 257-262.

Borrill M (1976). Temperate Grasses. In: Evolution of Crop Plants (Simmonds N, ed.). Longman Press, Harlow, 137-142.

Bulinska-Radomska Z and Lester RN (1985). Relationships between five species of Lolium (Poaceae). Plant Syst. Evol. 148: $169-175$.

Bulinska-Radomska Z and Lester RN (1988). Intergeneric relationships of Lolium, Festuca, and Vulpia (Poaceae) and their phylogeny. Plant Syst. Evol. 159: 217-227.

Catalán P, Kellogg EA and Olmstead RG (1997). Phylogeny of Poaceae subfamily Pooideae based on chloroplast ndhF gene sequences. Mol. Phylogenet. Evol. 8: 150-166.

Charmet G and Balfourier F (1994). Isozyme variation and species relationships in the genus Lolium L. (ryegrasses, 
Graminaceae). Theor. Appl. Genet. 87: 641-649.

Charmet G, Balfourier F and Chatard V (1996). Taxonomic relationships and interspecific hybridization in the genus Lolium (grasses). Genet. Res. Crop Ev. 43: 319-327.

Charmet G, Ravel C and Balfourier F (1997). Phylogenetic analysis in the Festuca-Lolium complex using molecular markers and ITS rDNA. Theor. Appl. Genet. 94: 1038-1046.

Darbyshire SJ and Warwick SI (1992). Phylogeny of North American Festuca (Poaceae) and related genera using chloroplast DNA restriction site variation. Can. J. Bot. 70: 2415-2429.

Doyle JJ and Doyle JL (1990). Isolation of plant DNA from fresh tissue. Focus 12: 13-15.

Fearon CH, Hayward MD and Lawrence MJ (1983). Self-incompatibility in ryegrass. V. Genetic control, linkage and seed-set in diploid Lolium multiflorum Lam. Heredity 50: 35-45.

Francisco-Ortega J, Santos-Guerra A, Kim SC and Crawford DJ (2000). Plant genetic diversity in the Canary Islands: a conservation perspective. Am. J. Bot. 87: 909-919.

Gaut BS, Tredway LP, Kubik C, Gaut RL, et al. (2000). Phylogenetic relationships and genetic diversity among members of the Festuca-Lolium complex (Poaceae) based on ITS sequence data. Plant Syst. Evol. 224: 33-53.

Jauhar PP (1993). Cytogenetics of the Festuca-Lolium Complex: Relevance to Breeding. Springer-Verlag, Berlin.

Lannér C, Bryngelsson T and Gustafsson M (1996). Genetic validity of RAPD markers at the intra- and inter-specific level in wild Brassica species with n=9. Theor. Appl. Genet. 93: 9-14.

Loos BP (1993a). Morphological variation in Lolium (Poaceae) as a measure of species relationships. Plant Sys. Evol. 188: 87-99.

Loos BP (1993b). Allozyme variation within and between populations in Lolium (Poaceae). Plant Syst. Evol. 188: 101113.

Mantel N (1967). The detection of disease clustering and a generalized regression approach. Cancer Res. 27: 209-220.

McGrath S, Hodkinson TR and Barth S (2007). Extremely high cytoplasmic diversity in natural and breeding populations of Lolium (Poaceae). Heredity 99: 531-544.

Mirjalili SA, Bennett SJ and Poorazizi E (2008). A phenetic analysis on the genus Lolium (Poaceae) in Iran. Plant Sys. Evol. 274: 203-208.

Naylor B (1960). Species differentiation in the genus Lolium. Heredity 15: 219-233.

Nei M and Li WH (1979). Mathematical model for studying genetic variation in terms of restriction endonucleases. Proc. Natl. Acad. Sci. U. S. A. 76: 5269-5273.

Perrier X, Flori A and Bonnot F (1999). Data Analysis Methods. In: Genetic Diversity of Cultivated Tropical Plants (Hamon P, Seguin M, Perrier X and Glaszmann JC, eds.). CIRAD, Montpellier, 43-76.

Polok K (2007). Molecular Evolution of the Genus Lolium L. Studio Poligrafii Komputerowej SQL, Olsztyn.

Polok K, Ciaglo S and Cabrita L (2006). AFLP analysis of genetic similarity between the species of the genus Lolium. Biodiv. Res. Conserv. 3-4: 232-234.

Rohlf FJ (1998). NTSYS-PC 2.2. Numerical Taxonomy and Multivariate Analysis System. Exeter Software: Applied Biostatistics, New York.

Roldán-Ruiz I, Dendauw J, Van Bockstaele E, Depicker A, et al. (2000). AFLP markers reveal high polymorphic rates in ryegrasses. Mol. Breed. 6: 125-134.

Stammers M, Harris J, Evans GM, Hayward MD, et al. (1995). Use of random PCR (RAPD) technology to analyse phylogenetic relationships in the Lolium/Festuca complex. Heredity 74 (Pt 1): 19-27.

Terrell EE (1968). A Taxonomic Revision of the Genus Lolium. Technical Bulletin No. 1392, United States Department of Agriculture, Washington.

Thorogood D and Hayward MD (1992). Self-compatibility in Lolium temulentum L: its genetic control and transfer into $L$. perenne L. and L. multiflorum Lam. Heredity 68: 71-78.

Vieira EA, Castro CM, Oliveira AC, Iraja F, et al. (2004). Genetic structure of annual ryegrass (Lolium multiflorum) populations estimated by RAPD. Sci. Agric. 61: 407-413.

Williams JG, Kubelik AR, Livak KJ, Rafalski JA, et al. (1990). DNA polymorphisms amplified by arbitrary primers are useful as genetic markers. Nucleic Acids Res. 18: 6531-6535.

Yu K and Pauls KP (1993). Rapid estimation of genetic relatedness among heterogeneous populations of alfalfa by random amplification of bulked genomic DNA samples. Theor. Appl. Genet. 86: 788-794. 